\title{
Applying Flipped Learning Approach in the Teaching of Electronic CAD Technology
}

\author{
Gang Sun ${ }^{1, a, *}$, Zhenzhong Yu ${ }^{1, b}$ and Zhong Yang ${ }^{1, c}$ \\ ${ }^{1}$ School of Intelligent Science and Control Engineering, Jinling Institute of Technology, Hongjing \\ Dadao, Nanjing, China \\ a gangsun@jit.edu.cn, ${ }^{\mathrm{b}}$ nanfish@jit.edu.cn, ${ }^{\mathrm{c}} \mathrm{yz} @ j \mathrm{jit} . e d u . c n$ \\ *corresponding author
}

Keywords: Flipped Learning, Electronic CAD Course

\begin{abstract}
To face the pedagogical challenges in application-oriented higher education, the flipped learning (FL) has become a newly emerging instructional approach in university courses. Before class, the students learn the relevant knowledges individually through various online sources prepared by teacher. And then, they are engaged in classroom activities to discuss the issues concluded from the learning process with classmates or inductor and practice the teamwork and problem-solving skills. In this paper, the drawbacks of traditional teacher-centered instructional approach in teaching of electronic CAD technology course are analysed. To overcome the conflicts between urgent need of practical training and traditional in-class theory teaching in application-oriented course, the FL strategy is proposed and discussed. And the steps of applying the proposed flipped strategy to the electronic CAD technology course are described. The practical teaching results show that the FL approach can effectively motivate the engagement and self-confidence of the student. Moreover, the increasing in-class peer interaction, which aims at the problems feedback from each student, can dramatically improve the efficiency of knowledge transferring. The proposed approach help teacher teach students according to their level, and have obtained the positive feedbacks from both teacher and students.
\end{abstract}

\section{Introduction}

With the increasing development of the large-scale integrated circuit technology in decades, various of intelligent devices are born and benefiting from the sharp growth. These devices usually feature small size and heavy calculation payload, which require of the high density circuit and component placement in a limited area and more reliable electric chains to support the inboard high-speed information interaction. As an application-oriented higher education, such changes should be caught and used to adjust the goals of teaching. The electronic CAD technology course is one of the compulsory courses of automation. The aim of this course is to teach these students how to design a print circuit board (PCB) with the assistant from EDA software and train their skills on interactive routing. Your paper will be part of the journals therefore we ask that authors follow the guidelines explained in this example, in order to achieve the highest quality possible.

The traditional teaching approach for this course is teacher-centered. In class, all the participants are logging to the E-class platform. In this local area network, teacher can remote control all 
students' terminals and share the teaching screen content to terminals in real-time. By this way, teacher explains the function of each button and each menu first, and then shows how to use these commands through some demonstrations. After that, the teacher returns the control right of terminals to students and induct them to repeat the works that just demonstrated. This 'learn-first and then-practice' strategy seems reasonable, however, the feedbacks from teacher and student are completely opposite. The teacher thought his explanations of each command are clear and vivid, especially with demonstrations. But the students found that they couldn't remember what teacher taught in such limited teaching duration. They need to passively accepted plenty of knowledge without breaks, for example, finding out several specific commands from eight or more menu lists. Their minds may distracted and lose the points. But, if turning to the method that let students practice after each knowledge point and continue teaching after confirming that most students can handle it well, the in-class efficiency may decrease. This is only a tip of the iceberg. More analyses of the course are given below:

- Traditional teaching approach is teacher-centered. It considers that teacher should induct the in-class and out-class learning activities. In class, teacher explains very acknowledge points to students without taking their individual learning abilities into account. Students are usually in different levels. Some of them may thought these points are too easy, but some of them thought they need more time to understand. If the teacher pay more attention on the latter, the class efficiency may decrease and other students may lose their patients. Moreover, the screen to screen teaching process is a copy work that force students to follow the given way from teacher essentially. This type of teaching is not flexible and is not good for the development of students' personality.

- The interaction between teacher and students is few in practice procedure. In traditional class, teacher is the supervisor of in-class studying. So students feel shy or fear to ask the questions even these behaviors are encouraged by the teacher. They prefer to stay in 'safe place' that out of teacher's attention.

- An effective way to supervise the studying out of class is neglected. For these undergraduates, the spare time in university is organized by themselves. The lack of supervision makes them prefer to spend much time on what they really love, such as computer gaming, reading novels, taking exercise and so on. Because comparing with the major knowledge, the hobbies are indeed more funny and relaxed.

- The evaluation mechanism of this course is unreasonable. Homework by electric format file is used to evaluate whether the student understand the knowledge. However, it is very easy to copy. At the end of semester, a paper examination but not the actual operation is applied to test the software operation ability. And the students have to remember lots of commands and the form the command implementation which can easily obtained from the software helper in real operation scene. Nearly all the students dislike this type of evaluation.

- The laboratory computer hardware configuration cannot catch up with the software upgrading. In most Chinese university labs, the serve life of PC is $7-10$ years. But the update period of the CAD software, take Altium Designer which used in this course for example, is 6 months. The operator may feel uncomfortable when the software and hardware doesn't match. And it may increase the designing error rate.

From above, the explorations and improvements on traditional teaching approach of the application-oriented course are required. The aim of this innovation is creating a comfortable studying approach and environment for student according to their status and abilities and increasing the interactions between teachers and students. The training and evaluation mechanisms should be centered on the operation skill rather than rote.

In section 2, three popular innovative learning approaches are introduced and compared. Section 
3 presents the implementation of flipped learning in the electronic CAD technology course. Section 4 is the discussion of implementation. Finally, the conclusion is drawn in section 5.

\section{Flipped Learning Strategy}

The micro-lecture, massive open online courses (MOOC) and flipped learning are three new teaching approaches developed in decades. They are spreading around the world sharply benefiting from the new media and information technology[1]. The micro-lecture is based on the online teaching video which records the teaching procedure around one or more knowledge points[2]. Unlike a brief presentation, it is usually a $10-15$ minutes long video that is formatted for online and mobile learning. And students can access the resources anywhere. Obviously, the micro-lecture is only an assisted method to explain the key points to student. It is still part of a traditional class. Classroom teaching is required for connecting all the points mentioned in videos together. The introduction of book content, homework assignment and analysis are all carried out in the classroom. Thus, the micro-lecture only refers to the knowledge points teaching form, not the whole classroom procedure.

MOOC is a kind of opening course for sharing the knowledge around the world, all teaching procedure is implemented in a virtual space. The teacher record his course by some standards and upload it to the interactive user forums to support community interactions among students and teachers. Everyone can access these course videos and learn together. And it allowed other MOOCs to reuse and remix the learning resources. All the learning procedure including discussion, homework assignment and analysis is running in an online space. However, there are lots of challenges in implementation[3,4]. MOOC is a collective online course, but lack of a face-to-face communication. Every MOOCs can generate the learning package without the recognised standard which may create a chaotic environment. The number of participants is too large and the teacher is hard to guarantee a good teaching performance. The participants have to self-regulate and set their learning goals, which may hard for ordinary undergraduates without the supervision from parents and teachers. Due to the situation above, MOOC is not suitable for a close course which is only participated by intramural students.

Flipped learning[5-7] is defined as a "pedagogical approach in which direct instruction moves from the group learning space to the individual learning space, and the resulting group space is transformed into a dynamic, interactive learning environment where the educator guides students as they apply concepts and engage creatively in the subject matter." It is presented as a form of inverting the classroom. In this form, what was done in class traditionally is done before the class, and what was done at home is done in class now. The learning content and material are organised by teacher first, including the teaching video, little quiz, and any form of material that may help students to understand the content. Then these resources are delivered to students through chat group or email before the class. Students learn the content and do the test, then conclude and record their questions. In class, teacher and students work through problems, advance concepts and engage in assigned collaborative tasks. It allows students to independently study with materials on their own time and at their own space. The in-class time is freed up for active and collaborative application with the support from classmate and teacher. Teachers are relaxing from the mass prepare work and concentrating on the real problems that learners cannot workout.

The electronic CAD technology course is to teach students design PCB through EDA software Altium Designer. Most contents are about software operation and have very few connections with other major courses like circuit theory, digital circuit and analog circuit. In Altium Designer, operator uses schematic editor to draw the circuit with defined component symbols from libraries, and the connecting each component with the correct footprint. After preparation, all component 
footprint and electrical connection network are imported to the PCB file. Until now, the procedures are very easy to follow by the feedback from students, but the PCB editing is tough they said. In PCB editor, the placement of components is implemented first. And the following is the most important step, interactive routing and optimising. The operator need to manually connect all the pads and via with same net labels. There is no specific rules to follow but with some general instructions, therefore it is sometimes hard and confused for learners due to the lack of experience. The most proper way to tell the students how to route a PCB is instructing rather than teaching, which need more time to communicate and share the experience with teacher and classmates. Therefore, according to the course characteristic above and three novel teaching approaches just mentioned, the flipped learning is the most proper way that can be implemented in the electronic CAD technology course.

\section{Implementation of Flipped Course}

In this section, the flipped learning strategy is implied to the electronic CAD technology course. The detail of implementation is described below.

Study participants are undergraduate students of automation in their third year of study in Jinling institute of technology. The aim of this 2-hour class is to tell students how to customise a component symbol that not included in the existing libraries.

- Step 1: Preparing the learning materials. A short micro-video is recorded with the whole procedure of making a new component symbol in Altium Designer. That is a small 10-foot chip. First, add a new component in the schematic library file and rename the component. Then draw the frame of this component on the blank sheet and add all the foot pins to the edges of the frame. After correctly numbering and naming each pin by the datasheet, save the current file as a schematic library file. The next is to test the availability of the new component. Adding this file into the 'installed library' and drag this new component to the schematic sheet to see whether it is recognised by the software and available for use. The homework is to add other three new components' schematic symbols to the library.

- Step 2: Learning materials publication. The learning video and homework are uploaded to the chat group including all the class students for downloading. By the count of download times, teacher can know how many student have viewed this material. In the following days, teacher will answer the questions from the students, who have learned the materials, through email, message or chat group.

- Step 3: Preparing the class activities. Two days before the class, all homework is submitted to the teacher. Teacher conclude the problems, and prepare for class instructions and activities. From the homework, two issues are estimated. Some students confused with two items of pin properties 'Display name' and 'Designator'. 'Display name' is a text that describe the pin function, while 'Designator' is the unique number pairs to the physical pins of the chip. The latter owns the electrical nature and will be connected to the electrical nets. Another issue is minor that some students cannot input the special text symbols in the pin name, such as the characters with overbar ' $\overline{\mathrm{MX}}$ '. Therefore, teacher need to explain these two concepts in class time. And then assign some tasks referred to the advanced operations of component schematics symbol designing. For example, how to separate the large component which contains hundreds of pins to different small functional parts.

- Step 4: In-class activities. In class, students get the homework review comments and teacher analysis the issues. It may take 10 minutes. Then, students are separated to several groups. More complex works are assigned to each group which may induct students to a deeper thinking or advanced implementation of what they just learned. In the rest of the class, the 
groups work at the tasks under the supervision from the teacher. Teacher will answer the students' questions in real-time and give them the individual face-to-face instruction. At the end of the class, the teacher make the conclusion of the tasks.

- Step 5: Interaction out of the class. After class, students can get touch with teacher if they have any related troubles when implementing the what they learned from the course. This step can remove the gap between teachers and students as well as improving the teaching efficiency.

\section{Discussion}

By a one-seminar teaching practice, the feedbacks show that student perceptions of the flipped class instructional model are favourable and welcomed. Most students would like to take another flipped course in their future studying. They are comfortable with the self-directed learning, because they can arrange the learning schedule freely. Some students consider that the course change their perspectives on online learning which now can induct them to finish specific tasks. The in-class activities also contributed to the positive learning experience. It brings a fresh and new learning environment to the participants. One student said, "We were easy to complain that I don't have time for reading, but under this course configuration, I can get the points from a short studying duration, that's efficiency."

From the point of teachers, the advantages and disadvantages are existing simultaneously, but the former count for more. The advantages and improvements of the flipped class are concluded as follow:

- The efficiency of teaching and knowledge transferring is improved. With the carefully selected learning materials, the students can decide when and where to study. Studying when their mind and body are under the best condition can significantly enhanced the comprehension and absorption of knowledges. The learning video usually keeps in 5-10 minutes, which can prevent the feeling of fatigue when students have concentrated on some point for a long time.

- Teacher can teach students according to their levels now. In the self-learning stage, students record every problems. These problems are mostly different from each other according to their learning abilities. In class, students discuss their problems with teacher and classmates. That's the way that student can take a face to face interaction with teacher and receive an one-on-one instruction. When following a traditional way that work with an entire class, it is extremely hard to differentiate and meet the needs of each student.

- The student-center teaching approach helps students to look for a correct self-learning method in university studying. The goal of higher education is not just to impart knowledge, but rather to help students become the problem solvers who can keep a continuous learning ability. To learn the new knowledge, the student need to collect enough materials and select which are most helpful first. Then, in the learning procedure, they need to find more materials and tools to resolve the problems, even ask their classmates and teachers. This is just the way through the whole flipped learning procedure.

- Reducing the course requirement of the laboratory hardware. In class, the students are separated to several groups to discus and work on assigned task. The group member can take their personal laptops and sit around a big table, for example, one group one table. The classroom layout is no longer limited to the traditional laboratory, and the hardware configuration of personal laptop can meet most requirements of the EDA software. It's more flexible and convenient for a group teamwork in different types of classroom layout.

However, there are still some shortcomings in implementation need to be improved. Preparing and upgrading the high quality teaching materials is the first challenge. The learning package should be small but with high quality. The materials should explain the key points well, and ensure 
that most student can understand. The online materials should be available at least one week before the class to reserve enough time for students to access and study. Moreover, when the new vision of software is released, the special attention need to be drawn on what's new. And then adding the new characteristics to the learning materials. The second challenge is how to ask a good question in class and how to design a good quiz for self-learning test. In flipped class, teacher uses questions to induct student move to the deeper levels of understanding. And a good quiz can help teacher know when and where the student need a help or special concentration. The activities and quizzes should be aware and built on the information provided in the online materials. Thus, we need to continuously improve the questioning strategies and student can benefit from them greatly.

\section{Conclusion}

From an overall point, the flipped learning is well accepted by both teacher and students. This type of teaching reduces the teacher's press on course preparation and in-class teaching. And now teacher can pay more attentions on what students really need, which gives him a sense of accomplishment. For the students, they are learning to implement the knowledges in practice. They can discuss with classmates and teacher on some specific problems, and even they have chance to help or teach other students, which may effectively motive the student engagement.

\section{References}

[1] Kong, S. C., Looi, C. K., Chan, T. W. and Huang R. (2017). Teacher development in Singapore, Hong Kong, Taiwan, and Beijing for e-Learning in school education. Journal of Computers in Education, 4(1), 5-25.

[2] Pathak, B. K. (2016). Emerging online educational models and the transformation of traditional universities. Electronic Markets, 26(4), 315-321.

[3] MoocGuide. (2011). Benefits and challenges of a MOOC. Retrieved from http://0x9.me/Hhs7D (Accessed on March, 2017).

[4] Doherty, I., Harbutt, D. and Sharma, N. (2015). Designing and developing a MOOC. Medical Science Educator, 25, 177-181.

[5] Flipped Learning Network, Sophia. (2014). Growth in flipped learning: Transitioning the focus from teachers to students for educational success. Retrieved from http://0x9.me/aVgst (Accessed on March, 2017).

[6] Bergmann, J., Sams, A. (2012). Flip Your Classroom: Reach Every Student in Every Class Every Day[M]. Washington, DC: International Society for Technology in Education.

[7] Bergmann, J., Sams, A. (2014). Flipped Learning: Gateway to Student Engagement[M]. Washington, DC: International Society for Technology in Education. 